\title{
O discurso da criança como sujeito de direitos: perspectivas para a educação física na infância ${ }^{1}$
}

\begin{abstract}
Alexandre Freitas Marchiori
"Cada sociedade tem seu regime de verdade, sua 'politica geral' de verdade: isto é, os tipos de discurso que ela aceita e faz funcionar como verdadeiros; os mecanismos e instâncias que permitem distinguir entre os enunciados verdadeiros e falsos, a maneira como se sancionam uns e outros; as técnicas e procedimentos valorizados para a obtenção da verdade; o status daqueles que têm o encargo de dizer o que funciona como verdadeiro" (FOUCAULT, 1986).
\end{abstract}

\section{Introdução}

Conforme Leite (2009), a pessoa como "sujeito de direito" originou-se das correntes filosóficas que mais se propagaram com a Revolução Francesa (berço verdadeiro do jusnaturalismo e do iluminismo) e que gerou as três dimensões dos direitos fundamentais (a saber: liberdade, igualdade e fraternidade). E, daí o direito objetivo passou a ser criação e reflexo das mais diversas manifestações da personalidade humana. A autora propõe que o direito subjetivo, inerente a própria natureza humana, serviria como limite ético necessário para legitimar a atuação do Estado. Desta forma, a pessoa humana teria sido reduzida por ser simples elemento na relação jurídica.

Barretto (2006) indica que a razão "é posta como norma para o comportamento humano. Ela nos ensina a reconhecer a lei da natureza”. Segundo o autor:

Aqueles que negligenciam a lei da natureza, tornam-se uma ameaça à vida, à
liberdade e aos bens de todos os demais. [...] Uma extensa tradição, centrada na
definição do ser humano como um ser racional, identifica, assim, a liberdade
como aspecto determinante. Um ser racional é aquele capaz, não somente de
estabelecer uma relação meios-fins, mas de eleger seus próprios fins. [...] a
liberdade entendida como autonomia, tem sido o núcleo privilegiado das
considerações acerca do conteúdo dos direitos humanos. [...] Tais direitos
englobam certas condições sociais e econômicas indispensáveis ao exercício da

\footnotetext{
${ }^{1}$ Este trabalho tem conexão com a dissertação "Sujeito de direitos no cotidiano da Educação Infantil", contendo partes desse documento. Refiro-me à análise dos documentos oficiais e legislação. Trabalho a ser concluído até agosto de 2012, junto ao PPGE/UFES.
} 
autonomia. Alimentação, moradia, saúde, educação e emprego são alguns dos itens incorporados a essa nova versão dos direitos humanos (p. 246-247).

Podemos inferir desses conceitos, narrados por Barretto, que a criança não foi reconhecida historicamente como um sujeito capaz, racional e que tivesse condições de estabelecer seus próprios fins. Que essa caracterização do infante foi uma escolha baseada em condições históricas e econômicas que, à medida que a sociedade se modifica, novos condicionantes vão surgindo no contexto social e revelam condições de perceber a crianças sob novas perspectivas. Kuhlmann Jr e Fernandes (2004) ratificam essa produção da infância. Fato percebido, também, por Ariès (2006). Sendo assim, podemos considerar, também, que o discurso do sujeito de direitos passou a ser incorporado na visão e conceito de infância. Todavia, não é possível defender uma linearidade histórica, mas reconhecer a dinâmica e complexidade que caracterizam a humanidade.

Desta forma, a história da educação física, possivelmente, acompanhou esse processo de reconhecimento da criança como sujeito de direitos. Entretanto, também foi instrumento para consolidar a visão da criança em desenvolvimento e sujeito a ser socializado pelas práticas corporais, especialmente, no cotidiano escolar. $\mathrm{O}$ interessante a observar é a inserção da disciplina educação física na educação infantil. Como a visão preponderante até a década de 1990 era assistencialista, os parques infantis possuíam caráter de guarda das crianças e um espaço de brincadeiras e iniciação escolar. Desta feita, podemos dizer que não havia espaço para pensar aquela educação física pautada nos esportes, todavia, a psicomotricidade ${ }^{2}$ encontrou um campo fértil de atuação e consolidação dos seus preceitos fundantes (Grosso modo) ${ }^{3}$.

Para proporcionar uma melhor clareza, a história da Educação Física tem alguns marcos conceituais, predominantes em cada época da nossa sociedade. Num primeiro momento tivemos a ginástica como ponto de inserção na educação, sendo esta um instrumento para alcançar a "cognição"; a abordagem higienista e saúde como foco de atuação e

\footnotetext{
${ }^{2}$ Observe-se que próxima a abordagem desenvolvimentista podemos colocar a chamada psicomotricidade, ou educação psicomotora, que exerceu grande influência na EF brasileira nos anos 70 e 80 . Influência esta que está longe de ter-se esgotado [...] Essa proposta vem sendo criticada exatamente porque não confere à EF uma especificidade, ficando seu papel subordinado a outras disciplinas escolares. Nessa perspectiva o movimento é mero instrumento, não sendo as formas culturais do movimentar-se humano consideradas um saber a ser transmitido pela escola (BRACHT, 1999, p.79).

${ }^{3}$ No artigo publicado na Revista Zero a Seis, n. 19 "A Educação Física na Infância...” buscamos aprofundar essa discussão e o processo histórico da inserção do especialista (professor de Educação Física e Arte) na Educação Infantil. Ver site: www.periodicos.ufsc.br/index.php/zeroseis/issue/view/1108.
} 
como ponto legitimador das práticas da área. Bracht (1999) nos diz que "A constituição da educação física, ou seja, a instalação dessa prática pedagógica na instituição escolar emergente dos séculos XVIII e XIX, foi fortemente influenciada pela instituição militar e pela medicina" (p. 72).

M1980.

Marinho (1980), narrando a história da educação física no Brasil, indica que em 1893, a instrução pública no Distrito Federal é regulamentada, destacando o trecho: "Nos jardins de infância serão ministrados jogos infantis, exercícios graduados e acompanhados de canto". O artigo $6^{\circ}$, segundo o autor, dizia: "Os jardins de infância são estabelecimentos de primeira educação, onde crianças de ambos os sexos, de 4 a 7 anos, recebem em comum os cuidados que seu desenvolvimento físico, moral e intelectual reclamam" (p. 167).

Segundo Moraes (2009), foi no Brasil Império (1851) “a lei de n. ${ }^{\circ} 630$ inclui a ginástica nos currículos escolares”. Rui Barbosa preconizava a obrigatoriedade da Educação Física nas escolas primárias e secundárias, praticada quatro vezes por semana durante 30 minutos. O autor propõe que no Brasil República começa a profissionalização da Educação Física, tendo as políticas públicas voltadas, até os anos 60 , voltadas para o desenvolvimento das estruturas organizacionais e administrativas. Nos anos 70, marcado pelo governo militar, a Educação Física era usada, não para fins educativos, mas de propaganda do governo sendo todos os ramos e níveis de ensino voltados para os esportes de alto rendimento. Nos anos 80 a Educação Física vive uma crise existencial à procura de propósitos voltados à sociedade. Nos anos 90 o esporte passa a ser visto como meio de promoção à saúde acessível a todos manifestada de três formas: esporte educação, esporte participação e esporte performance (MORAES, 2009).

Esse processo histórico não deve ser visto linearmente, bem como as questões da infância e sua educação. Há sempre um processo discursivo de verdade, interesses econômicos e ideologias perpassando as questões da vida em sociedade. Como propõe Bracht (1999):

O corpo sofre a ação, sofre várias intervenções com a finalidade de adaptá-lo às exigências das formas sociais de organização da produção e da reprodução da vida. Alvo das necessidades produtivas (corpo produtivo), das necessidades 
sanitárias (corpo “saudável”), das necessidades morais (corpo deserotizado), das necessidades de adaptação e controle social (corpo dócil). O déficit de dignidade do corpo vinha de seu caráter secundário perante a força emancipatória do espírito ou da razão. Mas esse mesmo corpo, assim produzido historicamente, repunha a necessidade da produção de um discurso que o secundarizava, exatamente porque causava um certo mal-estar à cultura dominante. Ele precisa, assim, ser alvo de educação, mesmo porque educação corporal é educação do comportamento que, por sua vez, não é corporal, e sim humano. Educar o comportamento corporal é educar o comportamento humano (BRACHT, 1999, p. 71-72).

A história da educação infantil no Brasil possui um caráter assistencialista no atendimento à infância carente. Kuhlmann Junior (1998, p. 88) indica que a implantação de asilos, creches e jardins de infância deveriam contemplar o assistencialismo privado, tendo como referência o controle da população de rua (aspectos jurídicos e policiais), recolhimento e assistência da "infância" abandonada e questões médico-higienistas (controle da mortalidade infantil). Essa perspectiva também é confirmada por Quinteiro (2005) ao afirmar que "[...] a história da infância coincide com a história do atendimento às crianças em situação de risco, o que também contribui para a produção da imagem da criança pobre, que é sempre vista como uma ameaça social a ser contida" (p. 32).

As mudanças percebidas historicamente, proveniente das questões sociais e de comportamento a partir da década de 60, provocaram mudanças políticas no Brasil. Desta forma, a criança e sua educação passam a ocupar um lugar diferenciado, exigindo uma nova legislação e outras perspectivas para a educação infantil (grosso modo). Quinteiro (ibid.) indica o ano de 1979 como um possível marco na produção educacional acerca da criança e da infầncia brasileira, "subsumida a sociedade do adulto, orientada pelas rígidas regras do mercado capitalista, no qual a infância parece ser apenas uma de suas mercadorias" (p. 33).

O reconhecimento da criança como sujeito de direitos na legislação brasileira pode ser percebida a partir de 1988. Isso conforme análise dos documentos que norteiam a Educação Infantil e a legislação específica das questões da infância. Todavia, é no Estatuto da Criança e Adolescente (Lei 8069/90) que a expressão "sujeito de direitos" foi referendada à criança e ao adolescente. Esse conceito começa a indicar uma nova concepção (ou novo paradigma) de criança. É justamente essa abordagem que será apresentada a seguir, destacando alguns pontos que o professor de Educação Física pode se apropriar para desenvolver suas intervenções pedagógicas na Educação Infantil. 


\section{O processo de assimilação do discurso da criança como sujeito de direitos na legislação brasileira e nos documentos orientadores da educação infantil: elencando direitos}

A Constituição Federal (CF) de 1988 não traz a expressão "sujeito de direitos", porém reconhece que a criança é portadora de direitos. Isso pode ser percebido nos artigos 203, 204, 208 e 227. Desta forma, a CF/1988 reconhece a necessidade de proteção à infância, o direito de atendimento em creches e pré-escolas às crianças de zero a seis anos, o direito à vida, à saúde, à alimentação, à educação, ao lazer, à profissionalização, à cultura, à dignidade, ao respeito, à liberdade e à convivência familiar e comunitária, além de colocá-los a salvo (leia-se: proteção) de toda forma de negligência, discriminação, exploração, violência, crueldade e opressão. Esses direitos serão ratificados pelo Estatuto da Criança e do Adolescente.

A Lei 8069/90 (ECA), em seu artigo 30, determina que "a criança e o adolescente gozam de todos os direitos fundamentais inerentes à pessoa humana, sem prejuízo da proteção integral de que trata a Lei, assegurando-se lhes, por lei ou por outros, meios, todas as oportunidades e facilidades, a fim de lhes facultar o desenvolvimento físico, mental, moral, espiritual e social, em condições de liberdade e de dignidade". O artigo $4^{\circ}$ ratifica o artigo 227 da $\mathrm{CF} / 1988$, acrescendo o direito ao esporte. $\mathrm{O}$ artigo $6^{\circ}$ apresenta o reconhecimento da "condição peculiar da criança e do adolescente como pessoas em desenvolvimento".

Referente aos direitos fundamentais, o ECA/1990 reconhece que: a criança e o adolescente têm direito à liberdade, ao respeito e à dignidade como pessoas humanas em processo de desenvolvimento e como sujeitos de direitos civis, humanos e sociais garantidos na Constituição e nas leis (Artigo 15); o direito à liberdade compreende os seguintes aspectos: II - opinião e expressão; IV - brincar, praticar esportes e divertir-se (Artigo 16); o direito ao respeito consiste na inviolabilidade da insanidade física, psíquica e moral da criança e do adolescente, abrangendo a preservação da imagem, da identidade, da autonomia, dos valores, ideias e crenças, dos espaços e objetos pessoais (Artigo 17); a criança e o adolescente têm direito à educação, visando ao pleno desenvolvimento de sua pessoa, preparo para o exercício da cidadania e qualificação 
para o trabalho, assegurando-se lhes: I - igualdade de condições para o acesso e permanência na escola; II - direito de ser respeitado por seus educadores (Artigo 53); e a criança e o adolescente têm direito à informação, cultura, lazer, esportes, diversões, espetáculos e produtos e serviços que respeitem sua condição peculiar de pessoa em desenvolvimento (Artigo 71).

O trabalho de Bazílio e Kramer (2008) aborda com maestria algumas questões para entendermos esse documento e reconhecer particularidades nesse processo de reconhecimento dos direitos da criança. Bazílio (idem) descreve os princípios básicos dessa Lei: “criança e adolescente como pessoas em condição peculiar de desenvolvimento; a garantia da condição de sujeitos de direitos fundamentais $e$ individuais; e direitos assegurados pelo Estado e conjunto da sociedade como absoluta prioridade (grifos do autor) (p. 23).

A Lei de Diretrizes e bases da Educação Nacional (LDB), Lei n. 9496/1996, reconheceu, no artigo 21, que a educação básica é formada pela educação infantil, ensino fundamental e ensino médio. Reconhecendo que o processo de discussão dessa lei e as mudanças na legislação anterior foram afetadas pelo discurso da criança como sujeito de direitos, houve o reconhecimento do direito à educação infantil, porém, apenas o ensino fundamental foi obrigatório. No caso da pré-escola e creche ficou como opção da família.

Analisando os três volumes do RCNEI (1998) percebe-se como o conceito sujeito de direitos vai se delimitando. Todavia a expressão "sujeito de direitos" ainda não aparece nas publicações. No primeiro volume, a palavra sujeito está vinculada ao reconhecimento da criança como sujeito social e histórico:

\footnotetext{
A criança como todo ser humano, é um sujeito social e histórico e faz parte de uma organização familiar que está inserida em uma sociedade, com uma determinada cultura, em um determinado momento histórico. É profundamente marcada pelo meio social em que se desenvolve, mas também o marca. A criança tem na família, biológica ou não, um ponto de referência fundamental, apesar da multiplicidade de interações sociais que estabelece com outras instituições sociais (Texto adaptado do documento "Política nacional de educação infantil”. MEC/SEF/DPE/COEDI, dez/1994, p. 16-17).
}

Segundo consta, ao buscar a concepção de sujeitos, as crianças possuem uma natureza singular, que as caracteriza como seres que sentem e pensam o mundo de um jeito muito próprio. Nas interações que estabelecem desde cedo com as pessoas que lhe são 
próximas e com o meio que as circunda, as crianças revelam seu esforço para compreender o mundo em que vivem, as relações contraditórias que presenciam e, por meio das brincadeiras, explicitam as condições de vida a que estão submetidas e seus anseios e desejos. No processo de construção do conhecimento, as crianças se utilizam das mais diferentes linguagens e exercem a capacidade que possuem de terem idéias e hipóteses originais sobre aquilo que buscam desvendar. Nessa perspectiva as crianças constroem o conhecimento a partir das interações que estabelecem com as outras pessoas e com o meio. [...] A concepção de construção de conhecimentos pelas crianças em situações de interação social foi pesquisada, com diferentes enfoques e abordagens, por vários autores, dentre eles: Jean Piaget, Lev Semionovitch Vygotsky e Henry Wallon (BRASIL, 1998).

Nas últimas décadas, esses conhecimentos que apresentam tanto convergências como divergências, têm influenciado marcadamente o campo da educação. Sob o nome de construtivismo reúnem-se as idéias que preconizam tanto a ação do sujeito, como o papel significativo da interação social no processo de aprendizagem e desenvolvimento da criança. [...] O âmbito de Formação Pessoal e Social refere-se às experiências que favorecem, prioritariamente, a construção do sujeito, está organizado de forma a explicitar as complexas questões que envolvem o desenvolvimento de capacidades de natureza global e afetiva das crianças, seus esquemas simbólicos de interação com os outros e com o meio, assim como a relação consigo mesmas. O trabalho com este âmbito pretende que as instituições possam oferecer condições para que as crianças aprendam a conviver, a ser e a estar com os outros e consigo mesmas em uma atitude básica de aceitação, de respeito e de confiança. Este âmbito abarca um eixo de trabalho denominado Identidade e autonomia (BRASIL, 1998).

O RCNEI pretende apontar metas de qualidade que contribuam para que as crianças tenham um desenvolvimento integral de suas identidades, capazes de crescerem como cidadãos cujos direitos à infância são reconhecidos. Visa, também, contribuir para que possa realizar, nas instituições, o objetivo socializador dessa etapa educacional, em ambientes que propiciem o acesso e a ampliação, pelas crianças, dos conhecimentos da realidade social e cultural. Os direitos elencados de forma direta, considerando-se as especificidades afetivas, emocionais, sociais e cognitivas das crianças de zero a seis anos, a qualidade das experiências oferecidas que podem contribuir para o exercício da 
cidadania devem estar embasadas nos seguintes princípios: o direito das crianças a brincar, como forma particular de expressão, pensamento, interação e comunicação infantil; o acesso das crianças aos bens socioculturais disponíveis, ampliando o desenvolvimento das capacidades relativas à expressão, à comunicação, à interação social, ao pensamento, à ética e à estética; a socialização das crianças por meio de sua participação e inserção nas mais diversificadas práticas sociais, sem discriminação de espécie alguma; o atendimento aos cuidados essenciais associados à sobrevivência e ao desenvolvimento de sua identidade. A estes princípios cabe acrescentar que as crianças têm direito, antes de tudo, de viver experiências prazerosas nas instituições (BRASIL, 1998).

Os PNQEI têm por premissa o reconhecimento de que as crianças desde que nascem são: cidadãos de direitos; indivíduos únicos, singulares; seres sociais e históricos; seres competentes, produtores de cultura; e indivíduos humanos, parte da natureza animal, vegetal e mineral". Por conseguinte, reconhece os direitos: à dignidade e ao respeito; autonomia e participação; à felicidade, ao prazer e à alegria; à individualidade, ao tempo livre e ao convívio social; à diferença e à semelhança; à igualdade de oportunidades; ao conhecimento e à educação; a profissionais com formação específica; a espaços, tempos e materiais específicos; direitos básicos, inclusive o direito ao respeito às suas diversas identidades culturais, étnicas e de gênero.

Nos parâmetros de qualidade temos a indicação da transformação das práticas cotidianas na EI, buscando a garantia do direito das crianças de zero até seis anos à Educação Infantil de qualidade. Reforça a "função indissociável do cuidar/educar, tendo em vista os direitos e as necessidades próprios das crianças no que se refere à alimentação, à saúde, à higiene, à proteção e ao acesso ao conhecimento sistematizado". Bazílio e Kramer (2008) abordam essa questão e propõem observar o trabalho pedagógico que é atravessado por esses conceitos, bem como a amplitude do termo “educar". Esses autores falam das mudanças sociais na atualidade, sobre a perda da autoridade e a necessidade de políticas públicas e estratégias que incentivem os adultos a não desistirem de educar (p. 122).

Encontramos outras diretrizes que norteiam a intervenção pedagógica nos parâmetros de qualidade nas instituições de EI, indicando que as propostas pedagógicas contemplem 
princípios éticos, políticos e estéticos, a saber: os princípios éticos no que se refere à formação da criança para o exercício progressivo da autonomia, da responsabilidade, da solidariedade e do respeito ao bem comum; os princípios políticos no que se refere à formação da criança para o exercício progressivo dos direitos e dos deveres da cidadania, da criticidade e do respeito à ordem democrática; e os princípios estéticos no que se refere à formação da criança para o exercício progressivo da sensibilidade, da criatividade, da ludicidade e da diversidade de manifestações artísticas e culturais.

Seguindo nas análises das publicações do MEC, temos a "Política Nacional de Ed Infantil: pelos direitos das crianças de 0 a 6 anos à Educação" (PNEI). É interessante observar que o discurso da criança como sujeito de direitos está presente no texto, mas as questões desenvolvimentistas também são contempladas. Isso é de fácil percepção no trecho: "Pesquisas sobre desenvolvimento humano, formação da personalidade, construção da inteligência e aprendizagem nos primeiros anos de vida apontam para a importância e a necessidade do trabalho educacional nesta faixa etária. Da mesma forma, as pesquisas sobre produção das culturas infantis, história da infância brasileira e pedagogia da infância, realizadas nos últimos anos, demonstram a amplitude e a complexidade desse conhecimento. Novas temáticas provenientes do convívio da criança, sujeito de direitos, com seus pares, com crianças de outras idades e com adultos, profisssionais distintos da família, apontam para outras áreas de investigação. Neste contexto, são reconhecidos a identidade e o papel dos profissionais da Educação Infantil, cuja atuação complementa o papel da família. A prática dos profissionais da Educação Infantil, aliada à pesquisa, vem construindo um conjunto de experiências capazes de sustentar um projeto pedagógico que atenda à especificidade da formação humana nessa fase da vida".

O documento PNEI (2006) confirma que as formas de ver as crianças vêm, aos poucos, se modificando, e atualmente emerge uma nova concepção de criança como criadora, capaz de estabelecer múltiplas relações, sujeito de direitos, um ser sócio-histórico, produtor de cultura e nela inserido. $\mathrm{Na}$ construção dessa concepção, as novas descobertas sobre a criança, trazidas por estudos realizados nas universidades e nos centros de pesquisa do Brasil e de outros países, tiveram um papel fundamental. Essa visão contribuiu para que fosse definida, também, uma nova função para as ações desenvolvidas com as crianças, envolvendo dois aspectos indissociáveis: educar e 
cuidar. Tendo esta função, o trabalho pedagógico visa atender às necessidades determinadas pela especificidade da faixa etária, superando a visão adultocêntrica em que a criança é concebida apenas como um vir a ser e, portanto, necessita ser "preparada para" (BRASIL, 2006).

Com relação aos direitos, esse documento ratifica os direitos que estão previstos na Constituição Federal (1988), no ECA (1990) e na LDB (1996). Percebe-se o discurso articulador de políticas públicas voltadas para conclamar a mobilização pela efetivação do direito à educação infantil: "a autonomia dos entes federados e o regime de colaboração são dois princípios indissociáveis no sistema federativo brasileiro. $\mathrm{O}$ objetivo comum de garantir os direitos da criança, entre eles o direito à educação, só pode ser alcançado, portanto, mediante a cooperação entre a União, os estados, o Distrito Federal e os municípios, de acordo com as definições constitucionais e legais vigentes". Outro ponto observado corresponde à complexidade que envolve a infância e seus sujeitos. Há o alerta para mobilizar as diversas áreas de atuação do Estado: "a política de Educação Infantil em âmbito nacional, estadual e municipal deve se articular às políticas de Saúde, Assistência Social, Justiça, Direitos Humanos, Cultura, Mulher e Diversidades, bem como aos fóruns de Educação Infantil e outras organizações da sociedade civil".

$\mathrm{Na}$ sequência das análises, temos os "Critérios para um Atendimento em Creches que Respeite os Direitos Fundamentais das Crianças" (2009). Esse trabalho foi publicado pela primeira vez em 1995, sendo reconhecido pelo MEC como referência para nortear a educação infantil. Esse documento focaliza o atendimento em creche, para crianças entre 0 a 6 anos de idade. Na maior parte das creches, as crianças permanecem em tempo integral, voltando para suas casas diariamente. A creche, assim, caracteriza-se, quase sempre, pela presença de crianças menores de 4 anos e pelas longas horas que ali permanecem diariamente. (CAMPOS; ROSEMBERG, 2009).

O texto apresenta de forma bem objetiva quais seriam os direitos das crianças atendidas numa "creche que respeita a criança", elencando-os a partir da expressão "nossas crianças têm direito": à brincadeira; à atenção individual: procuramos respeitar as variações de humor das crianças; o ritmo fisiológico da criança: no sono, nas evacuações, nas sensações de frio e calor; crianças com dificuldades especiais recebem 
apoio para participar das atividades e brincar com os colegas; têm direito a momentos de privacidade e quietude; a um ambiente aconchegante, seguro e estimulante; ao contato com a natureza; à higiene e à saúde; a uma alimentação sadia; a desenvolver sua curiosidade, imaginação e capacidade de expressão: nossas crianças têm oportunidade de desenvolver brincadeiras e jogos simbólicos; nossas crianças têm direito de cantar e dançar; não reprimimos a curiosidade das crianças pelo seu corpo; não reprimimos a curiosidade sexual das crianças; ao movimento em espaços amplos: nossas crianças têm direito de correr, pular e saltar em espaços amplos, na creche ou nas suas proximidades; nossos meninos e meninas têm oportunidade de jogar bola, inclusive futebol; nossos meninos e meninas desenvolvem sua força, agilidade e equilíbrio físico nas atividades realizadas em espaços amplos; nossos meninos e meninas, desde bem pequenos, podem brincar e explorar espaços externos ao ar livre; nossas crianças não são obrigadas a suportar longos períodos de espera; os bebês não são esquecidos no berço; os bebês têm direito de engatinhar; os bebês têm oportunidade de explorar novos ambientes e interagir com outras crianças e adultos; as crianças pequenas têm direito de testar seus primeiros passos fora do berço; reservamos espaços livres cobertos para atividades físicas em dias de chuva; organizamos com as crianças aquelas brincadeiras de roda que aprendemos quando éramos pequenos; procuramos criar ocasiões para as famílias participarem de atividades ao ar livre com as crianças; a proteção, ao afeto e à amizade: nossa creche respeita as amizades infantis; nossa creche valoriza a cooperação e a ajuda entre adultos e crianças; seu autocontrole e aprender a lidar com limites para seus impulsos e desejos; explicamos as crianças os motivos para comportamentos e condutas que não são aceitos na creche; a expressar seus sentimentos: nossas crianças têm direito à alegria e à felicidade; nossos meninos e meninas têm direito a expressar tristeza e frustração; procuramos ensinar meninos e meninas como expressar e lidar com seus sentimentos e impulsos; o bem-estar físico e psicológico das crianças é um de nossos objetivos principais; ajudamos as crianças a desenvolver sua autonomia; sempre conversamos com as crianças sobre suas experiências em casa e no bairro; nossas crianças expressam seus sentimentos através de brincadeiras, desenhos e dramatizações; a manifestação de preconceitos de raça, sexo ou religião nos mobiliza para que procuremos incentivar atitudes e comportamentos mais igualitários na creche; a uma especial atenção durante seu período de adaptação à creche; a desenvolver sua identidade cultural, 
racial e religiosa: nossas crianças têm direito a desenvolver sua autoestima; meninos e meninas têm os mesmos direitos e deveres; nossas crianças, negras e brancas, aprendem a gostar de seu corpo e de sua aparência; respeitamos crenças e costumes religiosos diversos dos nossos; a creche é um espaço de criação e expressão cultural das crianças, das famílias e da comunidade; nossas crianças, de todas as idades, participam de comemorações e festas tradicionais da cultura brasileira: carnaval, festas juninas, natal, datas especiais de nossa história; nossas crianças visitam locais significativos de nossa cidade, sempre que possível: parques, museus, jardim zoológico, exposições.

O último texto analisado corresponde ao documento norteador da Educação Infantil do município de Vitória "Um outro olhar" (2006). Basicamente, o princípio regente do texto é o reconhecimento da criança como sujeito de direitos, bem como os sujeitos presentes na Educação Infantil.

Se este era um risco diante de tantas impossibilidades da afirmação dos profissionais enquanto sujeitos históricos, tornou-se desafiante a tentativa de superar os modos cristalizados de participação, a formatação da fala, a regulação das idéias. Nestes momentos de intensa participação, foram compartilhadas as angústias, as dificuldades, as utopias por uma Educação Infantil construída pelas vias do reconhecimento do outro como sujeito de direitos: direito a uma educação pública de qualidade para todos, direito ao acesso a diferentes saberes e culturas, direito a condições dignas de trabalho e a salários justos, direito à palavra, direito à alegria de ensinar e de aprender (SEME, 2009).

Com relação à criança como sujeito de direitos, o documento faz um apanhado histórico sobre a construção desse novo paradigma. Reconhece a disparidade entre o discurso legal e sua efetivação na realidade brasileira:

\footnotetext{
"Num país cuja legislação tornou-se modelo exemplar a tantas nações, parece redundante nomear a criança como "sujeito de direitos". Porém, a realidade demonstra que estamos muito distantes de efetivar tal asserção legal e que a maioria das crianças brasileiras encontram-se submetidas às mais grotescas formas de exploração e negação de sua infância" (p. 66).
}

A garantia do direito sempre remete a um dever, ou seja, uma vez reconhecida a cidadania de cada um, o exercício efetivo do direito promove o bem-comum e a cumplicidade do exercício da cidadania. Isto implica dizer que, concomitantemente, o 
sujeito de direitos é também um sujeito de deveres. $O$ acesso ao direito e o reconhecimento como sujeito de direitos requer uma cultura de respeito, de solidariedade e de cumplicidade com o outro e com a realidade que os circunda (SEME, 2006).

Reconhecer a criança como sujeito de direitos, como cidadã, é reconhecê-la como artífice na construção de um mundo compartilhado no qual sua ação, sua palavra, sua cultura, sua história são respeitadas e ouvidas como síntese de uma experiência social atravessada pela sua condição de classe, etnia, gênero, idade etc. [...] uma concepção que reconheça as crianças como atores sociais que têm o brincar e os diferentes saberes como a chave para se fazer a experiência de mundo. De outro modo, podemos afirmar que o reconhecimento da criança como sujeito de direitos requer obrigações públicas que garantam o direito de viver a infância com dignidade em todos tempos e espaços, a ter acesso às diferentes práticas culturais, direito ao desenvolvimento pleno e direito a uma educação infantil de qualidade para todos (SEME, 2006).

O documento norteador da educação infantil de Vitória (SEME, 2006) traz como direitos: o reconhecimento da criança como sujeito social e histórico, o direito da criança brincar, o acesso a aprendizagens significativas, o contato com o acervo cultural da sociedade, à apropriação dos diferentes conhecimentos historicamente acumulados, de manifestar-se como criança em todos os tempos e espaços institucionais, de brincar com a realidade e desenvolver as diferentes linguagens (plástica, oral, escrita, corporal etc.), de partilhar suas experiências através de sua maneira de pensar, sentir e interagir. Tal perspectiva está fundada no embricamento do "cuidar e educar", no reconhecimento da criança como sujeito de direitos, garantindo-se o direito de ampliar as suas experiências de maneira prazerosa, garantir atenção e afeto, sobretudo nas situações que geram medo, insegurança e conflitos. Trata-se de respeitar a criança como pessoa humana.

Perspectivas para a educação física na infância 
A EF na Educação Infantil necessita, juntamente com as outras áreas de conhecimento, reconhecer o caráter transitório da infância e as especificidades desse sujeito criança. Nesse sentido, devem-se reconhecer, também, os direitos que a sociedade tem declarado pertencer às crianças, tais como o direito à vida, à educação, ao lazer, à cultura, objetivando alcançar o desenvolvimento físico, mental, moral, espiritual e social. Notase a prerrogativa do sujeito em desenvolvimento nesse discurso, um sujeito biológico, social, cultural e histórico que se forma ao passar dos anos. Isso pode ser percebido claramente quando se afirma o preparo para o exercício da cidadania e qualificação para o trabalho. Contudo, percebe-se, ainda, o caráter do presente, ou seja, a intervenção e experiência no contínuo da vida.

Dentre esses direitos, encontram-se o direito ao esporte, à informação, cultura, lazer, diversões, espetáculos. Não resta dúvidas quanto a esses conteúdos serem abordados e tratados por professores de EF. Podemos inferir que tanto a prática e/ou vivência dos conteúdos da Cultura Corporal possibilitam a formação do praticante, bem como seus espectadores. Trata-se de constituir um referencial cultural válido para a sociedade, ou seja, alimenta-se a cultura de consumo desses "bens culturais" e possibilita a manutenção do esporte espetáculo, seja por seus futuros atletas ou seus torcedores. Bracht (1999) contribui para refletirmos sobre essas questões ao propor que a tarefa da escola e especificamente da EF é "introduzir os indivíduos no universo da cultura corporal ou de movimento de forma crítica" (p. 83).

Para realizar tal tarefa (reportando-se às teorias progressistas da EF - os sujeitos poderão agir autônoma e criticamente na esfera da cultura corporal ou de movimento e também agir de forma transformadora como cidadãos políticos) é fundamental entender o objeto da EF, o movimentar-se humano, não mais como algo biológico, mecânico ou mesmo apenas na sua dimensão psicológica, e sim como fenômeno histórico-cultural. Portanto, essa leitura ou esse entendimento da educação física só criará corpo quando as ciências sociais e humanas forem tomadas mais intensamente como referência. No entanto, é preciso ter claro que a própria utilização de um novo referencial para entender o movimento humano está na dependência da mudança do imaginário social sobre o corpo e as atividades corporais (BRACHT, 1999, p. 81). 
Essa proposição do autor nos ajuda a pensar a criança como sujeito de direitos, este que conhece vivenciando experiências, mergulhando no mundo que lhes apresentam. Tratando-se da Educação Infantil, temos experiências externas à escola ${ }^{4}$, mas, também, as oferecidas no cotidiano infantil. Desta forma devemos considerar o direito à atenção individual, a um ambiente aconchegante, seguro e estimulante, ao contato com a natureza, à higiene e à saúde, a uma alimentação sadia, a desenvolver sua curiosidade, imaginação e capacidade de expressão, a desenvolver brincadeiras e jogos simbólicos, de cantar e dançar, a sanar a curiosidade pelo seu corpo e a curiosidade sexual, de correr, pular e saltar em espaços amplos, a oportunidade de jogar bola, inclusive futebol; nossos meninos e meninas desenvolvem sua força, agilidade e equilíbrio físico nas atividades realizadas em espaços amplos; nossos meninos e meninas, desde bem pequenos, podem brincar e explorar espaços externos ao ar livre.

Seguindo a argumentação e reconhecimento dos direitos, temos a creche como um espaço de criação e expressão cultural das crianças, das famílias e da comunidade. Isso nos ajuda a pensar que há produção de cultura, não apenas externo ao ambiente educacional, mas a partir dos sentidos que as crianças dão às práticas desenvolvidas entre elas e os adultos. Reconhece-se a necessidade de proteção, afeto, bem-estar físico e psicológico das crianças, contudo não inviabiliza uma abordagem que prime pelo desenvolvimento da autonomia, autoestima, da identidade cultural, racial e religiosa das crianças. Os documentos analisados apontam para o reconhecimento das diferentes manifestações culturais presentes na sociedade brasileira e a necessidade de respeitar essas diferenças e oferecer condições às crianças vivenciar/experienciar as comemorações e festas tradicionais dessa cultura: carnaval, festas juninas, natal, datas especiais de nossa história.

Segundo Darido (2003), há várias concepções coexistindo na área da Educação Física, objetivando romper com o modelo mecanicista. A autora destaca a abordagem desenvolvimentista, que se caracteriza por ter seus conteúdos desenvolvidos segundo uma ordem de habilidades, sendo: habilidades básicas locomotoras (andar, correr, saltar, saltitar), e manipulativas (arremessar, chutar, rebater, receber) e de estabilização (girar,

\footnotetext{
${ }^{4}$ Reconheço que as experiências são partilhadas pelos diferentes sujeitos da sociedade e acontecem em qualquer momento da vida em sociedade. Não podemos deixar de reconhecer, ainda, os processos de subjetivação e os discursos de verdade (FOUCAULT, 1986) que atravessam as relações humanas.
} 
flexionar, realizar posições invertidas). Os movimentos específicos são mais influenciados pela cultura e estão relacionados à prática dos esportes, do jogo, da dança $\mathrm{e}$, também, das atividades industriais. A outra abordagem corresponde à interacionistaconstrutivista. Esta considera o conhecimento que a criança já possui, pois se trata de uma especialista em brinquedo. "Deve-se, deste modo, resgatar a cultura de jogos e brincadeiras dos alunos envolvidos no processo ensino-aprendizagem, aqui incluídas as brincadeiras de rua, os jogos com regras, as rodas cantadas e outras atividades que compõem o universo cultural dos alunos. O jogo é considerado o principal modo de ensinar, é um instrumento pedagógico, um meio de ensino, pois enquanto joga ou brinca a criança aprende. Sendo que este aprender deve ocorrer num ambiente lúdico e prazeroso para a criança".

Darido (Idid.) segue caracterizando a crítico-superadora, considerando-a por seu caráter ou "projeto político-pedagógico". Tem como característica provocar o aluno a transcender "os conhecimentos do senso comum" e ampliar o acervo de conhecimento. "A Educação Física é entendida como uma disciplina que trata de um tipo de conhecimento denominado de cultura corporal que tem como temas o jogo, a ginástica, o esporte e a capoeira”. A quarta abordagem é a sistêmica, na qual a função da Educação Física na escola não está restrita ao ensino de habilidades motoras e desenvolvimento das capacidades físicas. A autora indica que "os conteúdos oferecidos na escola para integrar e introduzir o aluno na cultura corporal/movimento não diferem das demais abordagens: o jogo, o esporte, a dança e a ginástica". Tem como característica a importância da vivência, da experimentação dos movimentos em situação prática, além do conhecimento cognitivo e da experiência afetiva advindos da prática de movimentos.

Desta forma, a educação física na educação infantil, ao observarmos os preceitos ou indicações dos direitos da criança nos documentos analisados, estaria se apropriando das diferentes abordagens para suprir um fazer pedagógico que contemplasse as múltiplas linguagens da infância, as especificidades dos diferentes sujeitos presentes nesse nível da educação básica. Percebe-se, se considerarmos os termos chaves das abordagens ${ }^{5}$, que há tanto a necessidade de transitar pelas diferentes perspectivas da $\mathrm{EF}$, quanto a

\footnotetext{
${ }^{5}$ Grosso modo, temos a desenvolvimentista: estímulo das habilidades; interacionista-construtivista: construção do conhecimento; crítico-superadora: sujeito crítico e político; sistêmico: vivência e experiência.
} 
impossibilidade de recorrermos a apenas uma abordagem. Trata-se do reconhecimento da complexidade da infância e suas particularidades.

\section{Considerações Finais}

A cultura corporal, tampouco outra abordagem da EF, não consegue abarcar a complexidade da Educação Infantil sozinha. Há necessidade de diálogos com outras concepções e um transitar entre as diferentes perspectivas de formação humana que cada corrente pedagógica assume. O discurso do desenvolvimento integral da criança se faz presente nesse universo educacional, bem como o reconhecimento desse sujeito brincante, um ser social e histórico, um sujeito de direitos.

Os professores de educação física, e demais sujeitos da educação infantil, necessitam reconhecer o direito das crianças de ter acesso a diferentes saberes e culturas; reconhecer que as crianças são atores sociais, sujeito social e histórico que têm o brincar e os diferentes saberes como a chave para se fazer a experiência de mundo.

A educação infantil deve oportunizar a vivência e acesso às diferentes práticas culturais, o acesso a aprendizagens significativas, o contato com o acervo cultural da sociedade, à apropriação dos diferentes conhecimentos historicamente acumulados, o direito de manifestar-se como criança em todos os tempos e espaços institucionais, o direito de brincar com a realidade e desenvolver as diferentes linguagens (plástica, oral, escrita, corporal etc.), o direito de partilhar suas experiências através de sua maneira de pensar, sentir e interagir. Trata-se do desafio de oferecer às crianças um ambiente de aprendizagem, onde suas experiências sejam prazerosas, afetivas e vividas na plenitude de suas capacidades.

Tendo as proposições de Kohan (2003) por base, reflito que só poderíamos capturar a alma da infância se nos tornarmos sujeitos brincantes, feito crianças, num infantilar. Só reconheceremos o outro "criança" se deixarmos nossos preconceitos e ouvirmos a voz de quem fala. Trata-se de um convite a percebermos as potencialidades da infância e seus sujeitos. Estes que produzem sentidos, portadores de sentidos e linguagens. Estes que trazem as marcas da cultura como identidade: as crianças. 


\section{Referências Bibliográficas}

ARIÈS, Philippe. História social da criança e da família. Rio de Janeiro: Editora LTC, 2006.

BARRETTO, Vicente de Paulo (Coordenação). Dicionário de filosofia do direito. São Leopoldo/RS: Unisinos; Rio de Janeiro/RJ: Renovar, 2006.

BAZÍLIO, Luiz Cavalieri; KRAMER, Sônia. Infância, educação e Direitos Humanos. São Paulo: Cortez, 2008.

BRACHT, Valter. A constituição das teorias pedagógicas da educação física. Cadernos Cedes, ano XIX, $\mathrm{n}^{\mathrm{o}}$ 48, Agosto, 1999. Disponível em: http://www.scielo.br/pdf/ccedes/v19n48/v1948a05.pdf. Acesso em: 03/03/2011.

BRASIL. Constituição (1988). Constituição da República Federativa do Brasil: promulgada em 5 de outubro de 1988. Contém as emendas constitucionais posteriores. Brasília, DF: Senado, 1988.

BRASIL. Lei nº 8.069, de 13 de julho de 1990. Estatuto da Criança e do Adolescente (ECA). Brasília, DF: 1990.

BRASIL. Lei $n^{\circ}$ 9.394/1996, de 20 de dezembro de 1996. Diretrizes e Bases da Educação Nacional. Estabelece as diretrizes e bases da educação nacional. Diário Oficial da União. Brasília, DF, 23 dez. 1996.

BRASIL. Ministério da Educação e do Desporto. Secretaria de Educação Fundamental. Referencial Curricular Nacional para a Educação Infantil - RCNEI. Brasília: MEC/SEF, 1998. 3v.: il.

BRASIL. Ministério da Educação. Secretaria de Educação Básica. Parâmetros Nacionais de Qualidade para a Educação Infantil. Brasília: DF, 2006. 2v.: il.

BRASIL. Ministério da Educação. Secretaria de Educação Básica. Política Nacional de Educação Infantil: pelo direito das crianças de zero a seis anos à educação. Brasília: MEC, SEB, 2006. 32 p. 
BRASIL. Ministério da Educação/Secretaria da Educação Básica. Indicadores da Qualidade na Educação Infantil. Brasília: MEC/SEB, 2009.

CAMPOS, Maria Malta; ROSEMBERG, Fúlvia. Critérios para um atendimento em creches que respeite os direitos fundamentais das crianças. Brasília: MEC, SEB, 2009. 44 p. : il. (1 ${ }^{\text {a }}$ Edição 1995).

DARIDO, Suraya Cristina. Educação física na escola: questões e reflexões. Rio de Janeiro: Guanabara Koogan, 2003.

FOUCAULT, Michel. Microfísica do poder. Rio de Janeiro: Graal, 1986.

KOHAN, Walter Omar. Infância: entre educação e filosofia. Belo Horizonte, MG: Autêntica, 2003.

KUHLMANN JR., Moisés. Infância e educação infantil: uma abordagem histórica. Porto Alegre: Mediação, 1998.

KUHLMANN JR., Moysés; FERNANDES, Rogério. Sobre a história da infância (p.1534). In: FARIA FILHO, L. M. (Org.) A Infância e sua educação: materiais, práticas e representações (Portugal e Brasil). Belo Horizonte: Autêntica, 2004.

LEITE, Gisele. O novo conceito de sujeito de direito. Revista Âmbito Jurídico.com, 2009. Disponível em: http://www.ambito-juridico.com.br/pdfsGerados/artigos/5971.pdf. Acesso em: 13/07/2010.

MARINHO, Inezil Penna. História geral da Educação Física. São Paulo: Companhia Brasil Editora, 1980.

MORAES, Luiz Carlos. História da Educação Física. Site www.cdof.com.br, 2009. Disponível em: http://www.cdof.com.br/historia.htm. Acesso em: 03/03/2011.

QUINTEIRO, Jucirema. Infância e Educação no Brasil: um campo de estudos em construção. (In) FARIA, Ana Lúcia Goulart; DEMARTINI, Zeila de Brito Fabri; PRADO, Patrícia Dias (Orgs.). Por uma cultura da infância: metodologias de pesquisa com crianças. 2. Ed. Campina, SP: Autores Associados, 2005. 
SEME - Secretaria Municipal de Educação. Gerência de Educação Infantil. Secretaria Municipal de Educação Infantil: um outro olhar. Vitória (ES): Multiplicidade, 2006. $104 \mathrm{p}$.

SEVERINO, Antônio Joaquim. Metodologia do trabalho científico. São Paulo: Cortez, 1996. 